\title{
Motivation and Habit Formation: An Exploration of Rock Climbing and Its Implications for Exercise Participation
}

\author{
Emmy Dagnan*, Natalie Michaels, Breanna DeKupier, Jacquelyn Lazzaro, Cosmo Morabbi, Tim Zerwic, Anna Marie \\ Bernard and Audrey Byland
}

School of Occupational Therapy, Belmont University, USA

*Corresponding author: Emmy Dagnan, School of Occupational Therapy, Belmont University, Nashville, Tennessee, United States

Submission: 監April 11, 2018; Published: 海 April 24, 2018

\begin{abstract}
The motivation and habits of rock climbers were investigated using mixed methodology in order to better understand exercise participation Forty-one patrons of a south eastern United States climbing gym completed a demographics form and adapted Sports Motivation Scale II (SMS-II), while thirty-six participants completed the Rock Climbing Motivation Survey (RCMS). Those with higher climbing frequency reported significantly higher levels of identified regulation than individuals who climbed less often $(\mathrm{p}=0.011)$. According to a thematic analysis, exercise balance and personal growth and challenges were the most commonly reported themes of motivation for rock climbing. The most frequently cited barriers were injury and time. Participants reported external motivators to climb upon initiation of the sport, but appeared to rely more on internal motivators to continue climbing. These findings, which are supported by current literature on physical activity, may be applicable to promoting exercise participation and maintenance.
\end{abstract}

Keywords: Rock wall climbing; Motivation; Participation; Habits

\section{Introduction}

Internationally, only $23 \%$ of adults satisfy exercise guidelines proposed by the World Health Organization (WHO) [1]. Given the known health benefits and increasing availability of rock climbing, participation in rock climbing as a means of exercise should be strongly encouraged [2-4]. Personal factors, such as motivation and habituation, are crucial to establishing habits and maintaining physical activity [5,6]. The Model of Human Occupation (MOHO) and Self-Determination Theory (SDT) were used to explore the motivation of rock climbers. MOHO addresses the impact of motivation upon habituation [7], while SDT delineates a motivation continuum applicable to exercise participation [812]. SDT categorizes motivation on a spectrum from most to least autonomous: intrinsic regulation, integrated regulation, identified regulation, introjected regulation, external regulation, and nonregulation [13].

The purpose of this study was to understand exercise participation by investigating the motivators for rock climbing and climbing habits. Two research questions were explored.

1. What motivates recreational rock climbers?

2. Are the motivators different among rock climbers according to their habits?

\section{Operational definitions}

For the purpose of this study, motivation is defined as the drive or desire to participate in a given activity, and habits are defined as the tendency to follow a routine of specific activity.

\section{Methods}

Forty-one patrons (19 men and 22 women) of an indoor rock climbing gym in the south eastern United States participated in an online Qualtrics survey. The survey consisted of a demographics form, an adapted version of the Sports Motivation Scale II (SMS-II), and the Rock Climbing Motivation Survey (RCMS). Each participant completed the adapted SMS-II; however, only 36 completed the RCMS. The SMS-II is a valid and reliable, 18 items Likert-type measure addressing motivation to participate in a particular sport according to SDT [14]. Founded on exercise adherence literature, the RCMS uses six open-ended questions to prompt responses regarding motivation to rock climb.

\section{Data Analysis}

The Mann-Whitney U compared quantitative data from the SMS-II, while a thematic analysis using NVivo 10 software evaluated qualitative information from the RCMS. 


\section{Quantitative analysis}

Participants were grouped into two groups for climbing frequency: high frequency was once per-week or more, and lower frequency was 3 time per-month or less. Those with higher climbing frequencies scored significantly higher levels of identified regulation than individuals who climbed less often $(p=0.011)$ (Figure 1). There were also differences between the two groups for the 3 of the reasons to practice rock climbing on the SMS II. The first was S3 "Because it is very interesting to learn how I can improve," with those climbing more frequently scoring significantly higher at the .05 level ( $\mathrm{p}=.031)$. The second was S12, "Because I have chosen this sport as a way to develop myself," with those climbing more frequently scoring significantly higher at the 0.005 level $(p=0.003)$. The third was S18, "Because it is one of the best ways I have chosen to develop other aspects of myself," with those climbing more frequently scoring significantly higher at the 0.05 level $(\mathrm{p}=0.043)$ (Figure 2).

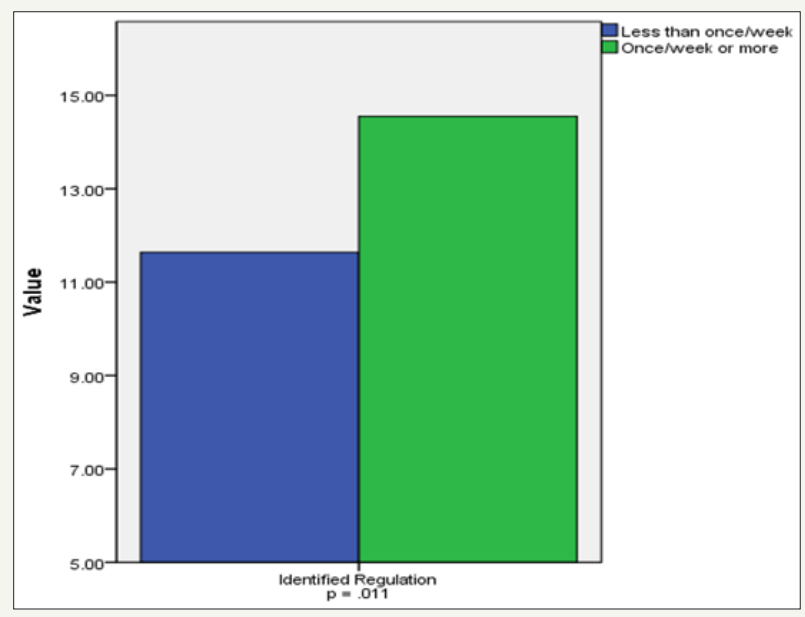

Figure 1: Mean identified Regulation scores for participants based on frequency of climbing

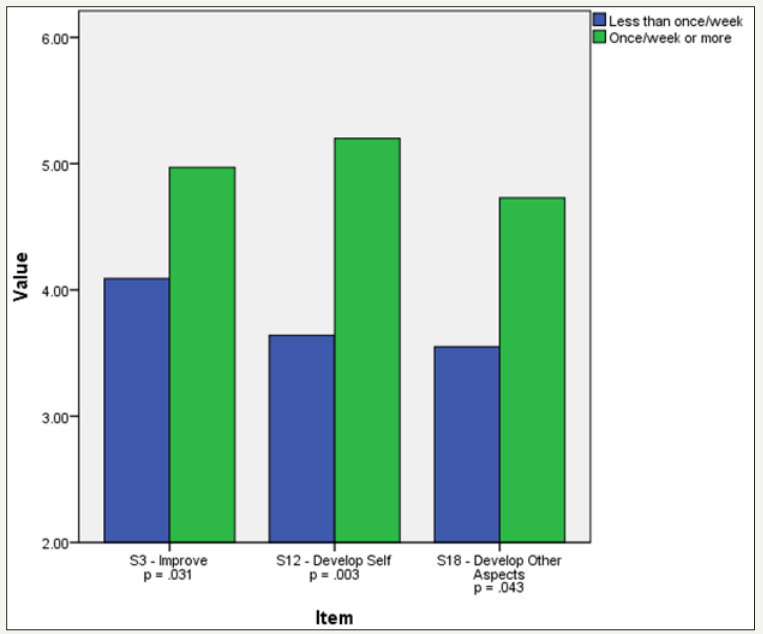

Figure 2: S3, S12, and S18 Scores for participants based on frequency of climbing.

\section{Qualitative analysis}

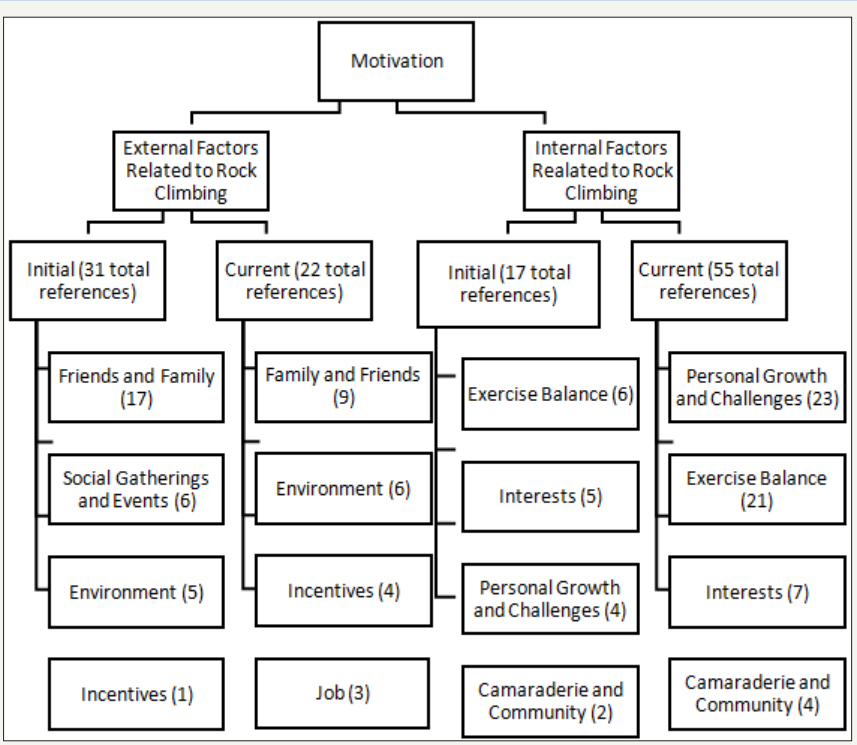

Figure 3: The hierarchy of coding for motivation themes. 
Responses from the RCMS were categorized into several themes addressing climbing motivation and barriers. Figure 3 displays a hierarchy of coding for motivation themes. Personal growth and challenges and exercise balance were the most reported subthemes of motivation. External factors related to climbing were most frequently reported for initiating the sport, while internal factors were most cited as reasons to currently climb.

Figure 4 demonstrates the hierarchy for barriers to climbing; injury and limited time/other obligations were the most frequently reported barriers to climbing.

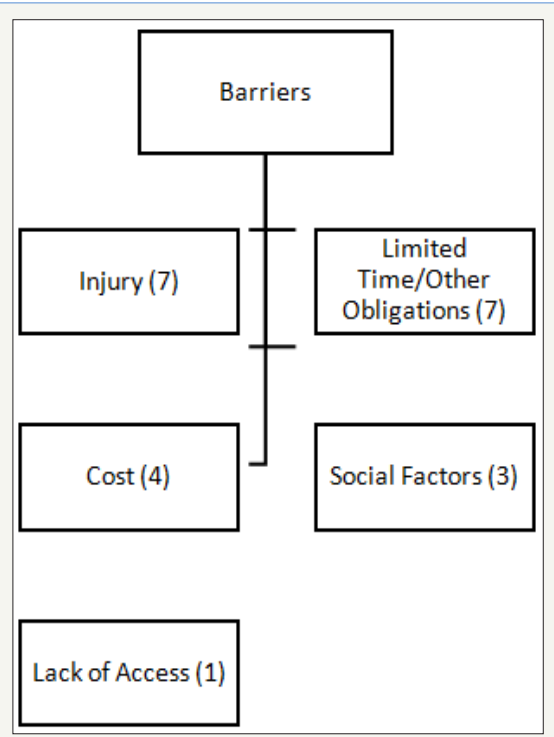

Figure 4: The hierarchy of coding for motivation themes.

\section{Discussion/Conclusion}

According to climbing frequency, participants reported significantly different levels of identified regulation, a relatively autonomous form of motivation based on internal values and goals $[8,13]$. These findings are supported by evidence that relatively autonomous motivation and habituation are related [9-11,15]. Rock climbers were initially motivated by family and friends (external factors), but continued to climb in order to fulfil personal growth and challenges, and exercise balance (internal factors). Climbing barriers were reported as due to injury and time. These findings are supported by literature, which explains that lack of time and social support commonly prevent exercise and sport participants from engaging in physical activity $[5,10,16]$. Awareness of these personal factors supports better understanding of rock climbing participation and may promote compliance to the physical activity recommendations of the WHO. Applying this knowledge to physical activity participation may contribute to an overall increase in health and wellness outcomes.

\section{References}

1. World Health Organization (2015) Physical activity.

2. Helt M (2014) climbing gyms and trends.

3. Muehlbauer T, Stuerchler M, Granacher U (2012) Effects of climbing on core strength and mobility in adults. Int J Sports Med 33(6): 445-451.

4. Gallotta M, Pietro Emerenziani G, Monteiro M, Iasevoli L, Iazzoni S, et al. (2015) Psychophysical benefits of rock-climbing activity. Percep Motor Skills 121(3): 675-689.

5. Morgan F, Battersby A, Weightman A, Searchfield L, Turley R, et al. (2016) Adherence to exercise referral schemes by participants-what do providers and commissioners need to know? A systematic review of barriers and facilitators. BMC Public Health.

6. Phillips LA, Gardner BA (2016) Habitual exercise instigation (vs. execution) predicts healthy adults' exercise frequency. J Health Psych 35(1): 69-77.

7. Kielhofner G (2002) Dynamics of human occupation. In: Kielhofner G, (Ed.), A model of human occupation: theory and application. ( $3^{\text {rd }}$ edn), Lippincott Williams \& Wilkins, Baltimore, USA

8. Hodge K, Lonsdale C, Jackson SA (2009) Athlete engagement in elite sport: an exploratory investigation of antecedents and consequences. Sport Psych 23(2): 186-202.

9. Ingledew DK, Markland D (2008) The role of motives in exercise participation. Psych and Health 23(7): 807-828.

10. Kinnafick F, Thøgersen-Ntoumani C, Duda JL (2014) Physical activity adoption to adherence, lapse, and dropout: a self-determination theory perspective. Qual Health Res 24(5): 706-718.

11. Gardner B, Lally P (2013) Does intrinsic motivation strengthen physical activity habit? Modeling relationships between self-determination, past behavior, and habit strength. J Behav Med 36(5): 488-497.

12. Sebire SJ, Standage M, Vansteenkiste M (2008) Development and validation of the Goal Content for Exercise Questionnaire. J Sport Exer Psych 30(4): 353-377.

13. Pelletier LG, Rocchi MA, Vallerand RJ, Deci EL, Ryan RM (2013) Validation of the Revised Sport Motivation Scale (SMS-II). Psych Sport Exer 14(3): 329-341.

14. Ryan RM, Deci EL (2000) Self determination theory and the facilitation of intrinsic motivation, social development, and well being. Amer Psych 55(1): 68-78.

15. Kerr JH, Houge Mackenzie S (2012) Multiple motives for participating in adventure sports. Psych Sport Exer 13(5): 649-657.

16. Ebben W, Brudzynski L (2008) Motivations and barriers to exercise among college students. J Exer Physio 11(3): 1-11. 
Creative Commons Attribution 4.0 International License

For possible submissions Click Here
RISM Imsin

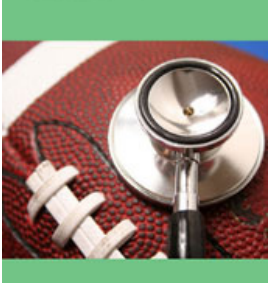

Research \& Investigations in Sports Medicine

\section{Benefits of Publishing with us}

- High-level peer review and editorial services

- Freely accessible online immediately upon publication

- Authors retain the copyright to their work

- Licensing it under a Creative Commons license

- Visibility through different online platforms 